\title{
Vantagens do caos brasileiro: o Brasil que Oswald de Andrade descobriu em Paris.
}

\section{Advantages of Brazilian chaos: the Brazil that Oswald de Andrade discovered in Paris.}

Artigo inédito

palavras-chave: Oswald de Andrade; Modernismo; arte brasileira: arte moderna

keywords: Oswald de Andrade; Modernism; Brazilian art; Modern art

* Universidade de São Paulo [USP].
Durante o ano de 1923, quando residiu em Paris, Oswald de Andrade teve contato com uma diversidade do que chamou de "ambientes intelectuais", atuando como agente divulgador do movimento de renovação artística e literária promovido em São Paulo pela Semana de Arte Moderna. Essa experiência produziu um alargamento de sua reflexão sobre a singularidade da formação cultural e da vida intelectual brasileiras, processo que culminaria na publicação do Manifesto da Poesia Pau-Brasil, pouco tempo depois de seu retorno ao país. Por meio da análise do texto de uma conferência, de cartas e de artigos enviados por Oswald de Andrade de Paris, este artigo discute o modo como as artes visuais participaram desse momento específico de sua experiência intelectual.

During the year of 1923, Oswald de Andrade lived in Paris, where he was in touch with different "intellectual environments", as he called them, acting as a promoter of the artistic and literary renewing movement started in São Paulo by the Semana de Arte Moderna. The experience he had in the French capital enlarged his reflection on the specificity of both Brazilian culture and intellectual life. This process culminated in the Manifesto da Poesia Pau-Brasil, published a few months after his return to Brazil. By means of the analysis of a conference text, together with letters and articles sent from Paris, this article discusses how the visual arts took part on that specific period of Oswald de Andrade's intellectual career. 
1923 foi um ano importante para a experiência intelectual de Oswald de Andrade. Depois da Semana de Arte Moderna, primeiro "round" enfrentado pelos "boxeurs" do Modernismo paulista ${ }^{1}$, entre março e dezembro daquele ano o escritor residiu em Paris. Àquela altura, ele já havia iniciado um romance secreto com Tarsila do Amaral, que acabara de montar um ateliê na capital francesa. Juntos, o casal Tarsiwald - como os apelidou depois Mário de Andrade - travou contato com um grupo variado de artistas, músicos, escritores e outras figuras da cena cultural parisiense, frequentando clubes de dança, cafés-concerto, galerias, apartamentos e ateliês por onde circulavam Jean Cocteau, Jules Romains, Blaise Cendrars, Darius Milhaud, Fernand Léger, Constantin Brancusi, Albert Gleizes, André Lhote, Pablo Picasso, Léonce Rosenberg, entre outros.

Se, à exceção de Blaise Cendrars, é difícil avaliar qual o grau de proximidade e envolvimento que Oswald de Andrade teve com cada um desses personagens, a análise das cartas e artigos enviados por ele ao Brasil, assim como do texto de uma conferência que pronunciou na Sorbonne naquele ano, permite avaliar como ele estava processando as experiências que vivia, digerindo-as de acordo com os interesses que o moviam enquanto intelectual engajado em um reflexão sobre a inserção de seu país na modernidade. Este artigo focaliza o modo como as artes visuais aparecem nesse momento específico da experiência intelectual de Oswald de Andrade. Momento que resultará, alguns meses depois de seu retorno ao Brasil, na escrita do Manifesto da Poesia Pau-Brasil. Momento que seu amigo Paulo Prado, companheiro de convivência na capital francesa, viu como sendo uma "descoberta" pessoal do Brasil ${ }^{2}$.

Para entender as relações estabelecidas por Oswald de Andrade junto ao meio artístico e intelectual parisiense, é preciso se perguntar sobre quais eram seus objetivos na capital francesa. As cartas que enviou a Mário de Andrade durante a viagem ${ }^{3}$ revelam, desde sua passagem por Lisboa, um empenho em criar relações com escritores que lhe pareciam mais próximos do tipo de renovação literária encampado pelos modernistas no Brasil. É o caso, por exemplo, da carta enviada de Lisboa, em 29 de janeiro de 1923, na qual Oswald de Andrade fala
60

Thiago Gil de Oliveira Virava

Vantagens do caos brasileiro:

o Brasil que Oswald de

Andrade descobriu em Paris.

1. Na coluna "Semana de Arte Moderna", publicada em 11 de fevereiro de 1922, no Jornal do Commercio, edição São Paulo, Oswald de Andrade atacava o que chamava de "academismo" e se referiu ao grupo de artistas e intelectuais que articulava a realização do evento como "boxeurs na arena": "Queremos mal ao academismo porque ele é o sufocador de todas as aspirações joviais e de todas as iniciativas possantes. Para vencê-lo destruímos. Daí o nosso galhardo salto, de sarcasmo, de violência e de força. Somos boxeurs na arena. Não podemos refletir ainda atitudes de serenidade. Essa virá quando vier a vitória e o futurismo de hoje alcançar o seu ideal clássico". ANDRADE, Oswald de. "Glórias de praça pública" [título atribuído]. In: BOAVENTURA, Maria Eugenia. 22 por 22: A Semana de Arte Moderna vista pelos seus contemporâneos. São Paulo: Editora da Universidade de São Paulo, 2008, p. 71.

2. No prefácio que ao livro Pau-Brasil (1925), Paulo Prado escreveu: "Oswald de Andrade, numa viagem a Paris, do alto de um atelier da Place Clichy umbigo do mundo - descobriu, deslumbrado, a sua própria terra". PRADO, Paulo. Poesia Pau-Brasil. In: ANDRADE, Oswald de. Poesias reunidas. 1a ed. São Paulo: Companhia das Letras, 2017, p. 15.

3. Oswald de Andrade enviou 14 correspondências ao amigo, entre cartas e cartões postais, desde a partida em dezembro de 1922 até maio de 1923. 
4. Revista publicada em Lisboa, entre 1922 e 1926, dirigida por José Pacheco.

5. ANDRADE, Oswald. 29 jan. 1923, grifos do autor. Para a transcrição das cartas, mantevese aqui os grifos, abreviações e estilo do original, apenas atualizando a ortografia ou corrigindo a grafia de nomes próprios, quando necessário, e acrescentando itálico às expressões estrangeiras e aos títulos de livros e revistas.

6. Inaugurada em 1915, a livraria foi frequentada por escritores como Guillaume Apollinaire, Paul Fort, Pascal Pia, Jules Romains, Leon-Paul Fargue, Louis Aragon, André Breton, André Gide, Paul Valéry, André Salmon, Max Jacob, Pierre Reverdy, Blaise Cendrars, Jean Paulhan, Tristan

Tzara, Jean Cassou, Valéry Larbaud, James Joyce, entre outros.

7. ANDRADE, Oswald de. [carta] 4 março 1923, Paris, França [para] ANDRADE, Mário de, São Paulo.

$2 \mathrm{fls}$, grifos do autor. Fundo

Mário de Andrade, Arquivo do Instituto de Estudos Brasileiros,

Universidade de São Paulo.

8. Ibidem
A geração surpreende. Contemporânea ${ }^{4}$ à nossa disposição. Manda-lhe Klaxon. E urgente, imprescindível, remete de suite, para o meu endereço em França (...) diversos exemplares de Pauliceia, o Messidor do Guy, se possível e 3 coleções ou 4 ou 5 de Klaxon. ${ }^{5}$

Em carta enviada já de Paris, em 25 de fevereiro de 1923, o escritor renova os pedidos de envio e acrescenta informações sobre seus primeiros contatos com escritores franceses. Ele envia ao amigo um autógrafo de Jules Romains, a quem se refere como "o $1^{\circ}$ amigo conquistado", e dá mostras de já ter conhecido a célebre livraria de Adrienne Monnier, La Maison des Amis des Livres ${ }^{6}$, onde sugere a Mário de Andrade que poderiam ser vendidos exemplares de Klaxon. Ao mesmo tempo, pergunta pelo andamento da tradução de seu romance Os condenados, publicado em 1922, e na qual Sérgio Milliet estaria trabalhando. Em 4 de março, o escritor volta a esse assunto, deixando transparecer alguma irritação com a demora nas notícias:

Esta carta exige resposta urgente. Les affairs sont les affairs, já dizia aquele besta do Mirabeau. Não tenho o endereço do Serge [Milliet] e por isso recorro a ti. Preciso com certa urgência da tradução francesa d'Os Condenados. Já terá o Serge terminado o trabalho que começou?

Se o tiver feito - peço ainda a ti, favor de amigo, ora! pelo amor de Deus! por quem é! Que os remeta a mim, sem perda de tempo! (...) A tradução ou qualquer notícia a respeito, espero dentro de 50 dias. Hoje são 4 de março, deve estar aqui a 24 de abril, no máximo. Certo? ${ }^{7}$

Na sequência, retoma os pedidos de envio de exemplares de Klaxon, aos quais acrescenta também a demanda por exemplares da nova fase da Revista do Brasil, além de dar notícias sobre sua atuação: "Tenho feito o possível por nós. Deixei na mesa de trabalho de Jules Romains o meu volume de Pauliceia. Insistência dele. Conhece o espanhol, quer decifrar. Pior para ti!"8.

Por esses trechos, percebe-se o quanto Oswald de Andrade pretendia assumir o papel de agente divulgador, em Paris, da renovação modernista no Brasil, procurando colaboradores, tradutores para seu 
romance Os condenados ${ }^{9}$, editores e distribuidores para os livros de seus colegas e para as revistas Klaxon e Revista do Brasil. Nesse sentido, ele foi um elemento importante do que se poderia chamar de uma "missão" brasileira em Paris.

A existência de uma comunidade de artistas brasileiros residentes em Paris não era, naturalmente, algo novo. Mas, naquele ano de 1923, encontrava-se reunido na capital francesa um grupo que, embora heterogêneo, unia-se pelo objetivo comum de conhecer e se integrar às correntes artísticas modernas, buscando reconhecimento junto a um ambiente que depois seria descrito pela noção difusa de "Escola de Paris" ${ }^{10}$. Além disso, era um grupo que, em alguns casos mais, em outros menos, mostrava-se também engajado na divulgação da cultura brasileira.

Dessa "missão" brasileira em Paris, além de Oswald de Andrade, fizeram parte, por períodos variados, também os músicos Sousa Lima, Villa-Lobos e Fructuoso Vianna, os escultores Victor Brecheret e Celso Antônio, os pintores Vicente do Rego Monteiro, Tarsila do Amaral e Di Cavalcanti, o jornalista, poeta e futuro crítico de arte Sérgio Milliet, entre outros ${ }^{11}$. Muitos deles tinham na figura do embaixador brasileiro Luiz Martins de Souza Dantas um importante esteio diplomático e, em alguns casos, até mesmo financeiro.

Souza Dantas foi um articulador importante para a inserção desse grupo de artistas e escritores em busca de espaço no concorrido cenário cultural da capital francesa. As relações com grupos sociais a que sua posição diplomática lhe dava acesso, somadas ao entusiasmo com que individualmente se dedicava à promoção da cultura brasileira, faziam do embaixador uma figura estratégica para aqueles artistas $^{12}$. Para um banquete oferecido em 24 de julho de 1923, celebrando sua nomeação como embaixador, Souza Dantas convidou uma lista de escritores e artistas ligados ao que se entendia ser a vanguarda parisiense do momento, convite este que teria sido uma sugestão de Oswald de Andrade ${ }^{13}$. A articulação promovida pelo escritor mostra a consciência que ele tinha da importância de fazer penetrar ideias modernas em órgãos oficiais, ainda que fora do país. Era parte da luta dos modernistas de São Paulo conquistar esses espaços ${ }^{14}$. E o banquete promovido por Souza Dantas pode ser entendido como uma espécie de "oficialização" da articulação que já vinha sendo feita informalmente entre artistas e escritores brasileiros e a vanguarda parisiense.

\section{Thiago Gil de Oliveira Virava}

Vantagens do caos brasileiro:

- Brasil que Oswald de

Andrade descobriu em Paris.

9. Após a chegada de Sérgio

Milliet a Paris, sem a tão

desejada tradução, em carta de

18 de abril de 1923, Oswald de

Andrade menciona tê-la deixado

a cargo de Mathilde Pomès.

10. É dentro dessa perspectiva que Marta Rossetti Batista analisa o que chama de "colônia brasileira" na capital francesa, dando destaque ao ano de 1923. Cf. BATISTA, Marta Rossetti. Os artistas brasileiros na Escola de Paris: anos 1920. São Paulo: Editora 34, 2012, p. 180-213

11. Cada um desses personagens viajara a Paris por meios diversos, a maior parte com financiamentos particulares, como é o caso de Oswald de Andrade e Tarsila do Amaral. Do grupo mencionado acima, apenas Sousa Lima, Victor Brecheret e Celso Antônio eram mantidos, respectivamente, pelo Estado de São Paulo, no caso dos dois primeiros, e pelo Estado do Maranhão.

12. Tendo ingressado com 21 anos no Ministério das Relações Exteriores, Souza Dantas havia atuado como Ministro Interino das Relações Exteriores durante a Primeira Guerra Mundial, antes de ser nomeado embaixador brasileiro em Roma, em 1919. Desde esse período, Dantas já era conhecido dos artistas brasileiros em estágio na Europa, pelos auxílios prestados aos que precisavam de passaporte e outros documentos oficiais, ou mesmo de auxílio financeiro, como foi o caso de Victor Brecheret. Ele também dava suporte ao senador José de 
Freitas Valle, enviando-lhe notícias dos artistas contemplados pelo Estado de São Paulo com o Pensionato Artístico. Nomeado para a Embaixada Brasileira em Paris no final de 1922, a atuação de Dantas na capital francesa rendeu-lhe a qualificação de "o homem que conseguiu mostrar ao povo francês que o Brasil existia". Além de bem relacionado, o embaixador demonstrava uma atenção especial às artes; frequentava as exposições dos artistas brasileiros, inclusive comprando obras para ajudá-los; em resumo, Souza Dantas comparecia a todas as manifestações culturais de interesse que envolvessem o Brasil ou brasileiros na França. Era, portanto, um personagem importante, com cujo apoio certamente Oswald de Andrade contava para o sucesso de seus objetivos de divulgar, em Paris, a renovação intelectual de que ele participava no Brasil. Sobre a atuação de Souza Dantas no auxílio a artistas e escritores brasileiros em Paris, ver CAMARGOS, Marcia. Entre

a vanguarda e a tradição: os artistas brasileiros na Europa (1912-1930). São Paulo: Alameda, 2011, p. 124-131 e BATISTA, Marta Rossetti. Op. cit., p. 188.

13. Compareceram ao evento no restaurante Chez Joseph: Fernand Léger, André Lhote, Jean Giradoux, Jules Romains, Blaise Cendrars, Darius Milhaud, Jules Supervielle, além dos brasileiros Oswald de Andrade, Tarsila do Amaral, Sérgio Milliet, Victor Brecheret, Vicente do Rego Monteiro, Pinheiro Júnior lista para a revista Ariel ${ }^{15}$.

Mas esse não foi o único evento em que Oswald de Andrade buscou uma aproximação com instâncias oficiais de relações internacionais entre Brasil e França. Ele foi precedido pela conferência pronunciada pelo escritor, em 11 de maio de 1923, no anfiteatro Turgot, da Universidade Sorbonne, com o título "O esforço intelectual do Brasil contemporâneo”.

Conforme sugere Dilma Diniz ${ }^{16}$, Oswald de Andrade foi convidado para proferir uma conferência na Sorbonne pelo professor Georges Le Gentil, responsável por um curso de estudos brasileiros oferecido na universidade francesa naquele ano. E lá estava novamente o embaixador Souza Dantas, que havia sido o responsável pela conferência inaugural do curso, o que permite imaginar que pode ter sido por intermédio do embaixador que Oswald de Andrade obteve o convite para a conferência. Além disso, como sugere Marta Rossetti Batista, possivelmente foi também Souza Dantas quem apresentou Tarsila do Amaral e Oswald de Andrade a Valéry Larbaud e Jules Supervielle ${ }^{17}$, ambos colaboradores da revista Revue de l'Amérique Latine, que dois meses depois da realização da conferência publicou seu texto integral em francês.

A publicação do texto naquela revista certamente não foi uma casualidade. Ela permite imaginar que a conferência na Sorbonne não foi encarada por Oswald de Andrade como um evento restrito apenas a um interesse acadêmico no campo dos "estudos brasileiros". Ele se valeu do espaço que lhe foi dado para conectar sua exposição também ao processo de construção de uma nova ideia de latinidade na França, do qual a Revue de l'Amérique Latine era um dos principais espaços de difusão, em Paris. Editada na capital francesa e criada em janeiro de 1922, em seu primeiro número a revista apresenta o objetivo de, por meio da publicação da produção de "escritores, sábios e homens políticos franceses, hispano-americanos e brasileiros", propiciar ao leitor francês um resumo do que era a "vida intelectual, artística, econômica e social de todo o continente latino da América" ${ }^{18}$. Ao selecionar, traduzir e apresentar os ensaios e poemas publicados na revista, os editores preocupavam-se em criar conexões entre os autores do continente americano e o "espírito latino", procurando demonstrar, 
através daquela produção, a presença daquele espírito no continente americano. Forjando essa ligação, a revista proporcionava aos autores do continente americano uma oportunidade de reconhecimento e identificação ${ }^{19}$.

A circulação da ideia de latinidade, ou de "espírito latino", no ambiente cultural francês havia assumido uma dimensão importante depois da Primeira Guerra Mundial. Como demonstra Kenneth Silver, durante o conflito e nos anos seguintes, a ideia de latinidade estava diretamente conectada ao sentimento de hostilidade contra a Alemanha e contra o povo alemão, vistos como "bárbaros" dos quais era preciso se defender em todas as frentes. Mas o apelo aos sentimentos latinos contra a barbárie germânica projetava-se também enquanto uma defesa mais ampla, não restrita a um território ou nação específica. Quando, em abril de 1915, a Itália se incorporou aos países aliados, essa decisão foi celebrada simbolicamente como o casamento de Dante (representando o classicismo italiano) e Marianne (representando a República francesa), o que assumia uma significação moral e cultural ainda maior do que a importância militar da aliança, na medida em que ratificava "uma guerra de classicistas e Latinos contra os bárbaros de um modo que a França por si só não poderia fazer" ${ }^{20}$. Era a defesa da própria "civilização" contra a barbárie.

O uso do termo "latino", associado a "civilização", "Ocidente" e "humanidade", evocava ainda "um chamado à ordem e um apelo à família, em sentido amplo e nacional", penetrando na vida cultural parisiense por meio de uma literatura propagandística, que passou a dar preferência a temas ligados ao "Antigo" e ao "clássico", e por uma ampla variedade de figuras alegóricas, símbolos tradicionais e monumentos patrióticos esquecidos até aquele momento, mas que agora eram reativados ${ }^{21}$. A Revue de l'Amérique latine, assim como a Maison de l'Amérique Latine ${ }^{22}$, representava um movimento adicional na formulação ideológica do "espírito latino". Um movimento que se voltava para o outro lado do Atlântico.

Com esse contexto em mente, pode-se compreender melhor alguns aspectos do conteúdo da conferência "O esforço intelectual do Brasil contemporâneo”23. Em busca de vínculos junto ao meio intelectual francês, Oswald de Andrade procurou adequá-la tanto à possível expectativa dos interessados em um curso de estudos

\section{Thiago Gil de Oliveira Virava}

Vantagens do caos brasileiro:

o Brasil que Oswald de

Andrade descobriu em Paris.

e o próprio Souza Dantas. Cf. AMARAL, Aracy. Tarsila: sua obra e seu tempo. 3a ed. rev. e ampl. São Paulo: Ed. 34; Edusp, 2003, p. 110.

14. Essa consciência se manifestou, alguns anos depois, na formulação de um projeto para a criação de um Departamento de Organização e Defesa do Patrimônio Artístico do Brasil (DODEPAB) e, na década de 1930, em uma proposta de criação de um museu em São Paulo que acolhesse obras de arte "clássica" e "moderna". Sobre o projeto do DODEPAB, ver CALIL, Carlos Augusto. Sob o signo do Aleijadinho. Blaise Cendrars, precursor do patrimônio histórico.

Arquitextos, São Paulo, ano 13, n. 149.05, Vitruvius, out. 2012. Disponível em: <http://www. vitruvius.com.br/revistas/read/ arquitextos/13.149/4540>. Acesso em: 11 jan. 2018.

15. 0 texto foi publicado no número de outubro de 1923.

16. DINIZ, Dilma Castelo Branco. A gênese da Poesia Pau-Brasil: um escritor brasileiro na França. o Eixo e a Roda: Revista de Literatura Brasileira, Belo Horizonte, v. 9-10, p. 75-83, 20032004. Disponível em: <http:// www.periodicos.letras.ufmg. br/index.php/o_eixo_ea_roda/ article/view/3159>. Acesso em: 1 mar. 2018.

17. 0 primeiro é comentado com frequência na correspondência enviada por Oswald a Mário de Andrade, em 1923. Em carta de 
7 de março, o escritor, sempre se queixando de Sérgio Milliet, comenta seu primeiro encontro com Larbaud: "Ontem visitei Valéry Larbaud. É o Bom, na acepção gorda da palavra. Vai aprender o português para traduzir toda a geração, já que Serge Milliet continua a acreditar no preguiçoso Sr. Alfred de Musset". Poucas semanas depois, em carta sem data, mas anterior a 9 de abril, ele afirma:

"Atenção para Larbaud e Morand - amigos".

18. Revue de l'Amérique latine, n. 1, jan. 1922, p. 2.

19. Cf. BERCHENKO, Adriana. La Revue de l'Amérique latine en los años 20. América: Cahiers du CRICCAL, nº 4-5, p. 21-26, 1990.

20. SILVER, Kenneth E. Esprit de corps. The art of the Parisian Avant-Garde and the First World

War, 1914-1925. Princeton: Princeton University Press, 1989 , p. $92-100$.

21. Ibidem, p. 97-98.

22. Sobre a atuação desse espaço, inaugurado em Paris, em 29 de maio de 1923, ver BATISTA, Marta Rossetti. Op. cit., p. 167 et. seq.

23. Uma tradução do texto da conferência foi publicada na Revista do Brasil, n. 23, dezembro de 1923, porém com supressões e cortes de parágrafos inteiros em relação à versão da Revue de l'Amérique Latine. Como a versão utilizada no volume Estética e Política das Obras Completas brasileira desde fins do século 19, quanto ao "espírito latino" que movimentava parte dos debates culturais parisienses dos quais ele se aproximou.

Esse último aspecto se nota logo no primeiro parágrafo, quando Dom Quixote e Os Lusíadas aparecem lado a lado enquanto produtos de um "idealismo latino" que teria desembarcado na América do Sul com Cabral, trazendo junto "uma força latina de coesão, de construção e de cultura”. Essa força era representada pelo jesuíta, apresentado como herdeiro do "espírito de organização e de conquista" legado ao mundo latino pelo Império romano. O jesuíta era um "legionário" que veio à América lançar as "Missões" no Uruguai e fundar a cidade de Piratininga, "que devia engendrar a força e a riqueza de São Paulo de hoje"24.

Assim estava feita a costura entre a história do "mundo latino" e a história do Brasil, pela presença, na formação inicial do país, do "padre latino" e da cultura ibérica. Com isso, Oswald de Andrade arma um problema complexo, pois o suposto "espírito de organização e de conquista" do jesuíta tinha de conviver no Novo Mundo com outros elementos étnicos e culturais. Parte do conteúdo da conferência é uma tentativa de resolver esse problema e conciliar os elementos "latinos" e "bárbaros" que constituíam a sociedade brasileira. Daí a importância de "O esforço intelectual do Brasil contemporâneo" para o entendimento da experiência intelectual de Oswald de Andrade, uma vez que nessa conferência estão esboçadas, talvez pela primeira vez, algumas das principais questões que ele irá perseguir ao longo da década de 1920, às quais seus dois manifestos procuram responder. E, como será visto, ele reserva a parte final da apresentação para as artes visuais e a música, que tinham um papel a cumprir no enfrentamento daquelas questões.

Depois de criar um vínculo com o idealismo latino, a apresentação segue comentando a formação étnica e cultural do Brasil, que teria se dado, inicialmente, pela atuação de três elementos - o índio, o português e o padre latino. "O negro", complementa o escritor, "veio da África, pouco tempo depois". Dessa abertura da conferência, interessa destacar aqui o papel atribuído ao indígena e ao africano. A imagem da participação do indígena e do negro na formação do Brasil 
criada por Oswald de Andrade nesse momento oscila entre a submissão passiva à cultura imposta e o exotismo. Veja-se, por exemplo, o trecho em que o escritor comenta a importância da fé católica na constituição do que chama de "sociedade sul-americana":

Reconhecendo a eficácia da fé no bom êxito das suas empresas, o português, que, sozinho, logrou resistir ao missionário, deu-lhe, nas primeiras assembleias do continente descoberto, uma ascendência preponderante. $\mathrm{O}$ índio politeísta não tardou a agregar um novo deus à sua mitologia (oral) ${ }^{25}$, e o negro, habituado a ver em tudo manifestações sobrenaturais, deixou-se batizar com uma alegria de criança ${ }^{26}$.

Leitor de autores como Oliveira Vianna e Graça Aranha - ambos citados na conferência -, que apresentavam uma visão de indígenas e negros como elementos inferiores na formação da sociedade brasileira, Oswald de Andrade delineia no trecho citado uma visão no mínimo problemática do que foram os processos históricos da catequização indígena e do batismo cristão de africanos escravizados, que os destituía de suas origens espirituais e culturais. Processos de violência física e simbólica aparecem como assimilações passivas, desprovidas de qualquer conflito ou resistência. Em outros trechos da conferência, a participação de indígenas e negros na formação da cultura brasileira será novamente lembrada, dessa vez em chave um pouco diferente.

Um desses trechos é o argumento que sustenta a afirmação de que a literatura brasileira só havia alcançado uma realidade superior e nacional na obra de Machado de Assis. Embora reconheça que um "sentimento brasileiro" já existia nas obras de poetas e escritores como Basílio da Gama, Gonçalves Dias e José de Alencar, para Oswald de Andrade esses autores haviam falhado, especialmente Alencar, por projetarem uma imagem do indígena idealizada e falsa. Havia uma espécie de paradoxo que esses escritores brasileiros teriam alimentado, um paradoxo cuja origem remontava à reação dos primeiros portugueses diante da natureza tropical: "O português boquiabriu-se diante da natureza do mundo descoberto e, para exprimir seu entusiasmo, recorreu aos seus conhecimentos greco-latinos" ${ }^{27}$. Eis o paradoxo: a experiência singular e nova da vida nos trópicos era vertida em linguagem por meio de recursos que lhe eram estranhos. Até Machado de
66

Thiago Gil de Oliveira Virava

Vantagens do caos brasileiro:

o Brasil que Oswald de

Andrade descobriu em Paris.

de Oswald de Andrade foi a da Revista do Brasil, sempre que for citado aqui algum dos trechos suprimidos, isso será indicado em nota. A tradução desses trechos é nossa. Para os demais trechos citados, foi utilizada a versão da Revista do Brasil, segundo a edição das Obras Completas de Oswald de Andrade, indicando-se entre parênteses as supressões relevantes.

24. ANDRADE, Oswald de. 0 esforço intelectual do Brasil contemporâneo (1923). In: Estética e Política. Organização, introdução e notas Maria Eugenia Boaventura. 2a ed. rev. e ampl. São Paulo; Globo, 2011, p. 39.

25. No original em francês consta "mythologie orale".

26. ANDRADE, Oswald de. 0 esforço intelectual do Brasil contemporâneo (1923). Op. cit., 2011, p. 40.

27. Ibidem, p. 43. 
ARS Assis, os recursos expressivos de que os escritores brasileiros teriam ano 16 lançado mão em suas obras provinham unicamente "da influência de n. 33 importação" e por isso resultavam em obras incompletas.

Oswald de Andrade não avança em sua caracterização da singularidade do autor de Dom Casmurro no panorama do esforço intelectual brasileiro por ele traçado, limitando-se apenas a afirmar: "Machado de Assis, branco de epiderme e cumulado de louvores pelos brancos, obteve equilíbrio, devido ao seu sangue negro”. Na obra do escritor fluminense não haveria qualquer "desvio inútil de paisagem, nenhuma gafa lírica", sendo seus romances "nossas melhores obras de

28. Loc. cit.

29. Loc. cit. Na versão em francês, lê-se: “le nègre battait les premiers tambours, pour exprimer sa joie et sa peine".

30. ANDRADE, Oswald de. L'effort intellectuel du Brésil contemporain. Revue de l'Amérique Latine, Paris, ano 2, n. 5, p. 207, jul. 1923. 0 trecho citado foi suprimido da tradução publicada na Revista do Brasil. ficção" ${ }^{28}$. O realismo e a precisão de sua escrita teriam salvo Machado de Assis do idealismo loquaz de seus antecessores. Esse realismo teria origem, segundo Oswald de Andrade, no "sangue negro" do escritor, como se depreende do trecho a seguir, que antecede imediatamente suas considerações sobre Machado de Assis:

O negro é um elemento realista. Isto observou-se ultimamente nas indústrias decorativas de Dakar, na estatuária africana, posta em relevo por Picasso, Derain, André Lhote e outros artistas célebres de Paris, na antologia, tão completa, de Blaise Cendrars. De resto, ele, que vinha da África, não podia maravilhar-se diante da nossa paisagem. O português, ao chegar, fazia sonetos, e o negro, por seu turno, a fim de expressar suas alegrias ou mágoas, rufava nos urucungos. ${ }^{29}$

O mesmo negro apontado, poucos parágrafos antes, como pronto a ver em tudo manifestações sobrenaturais, é agora descrito como um elemento realista, sendo a presença do "sangue negro" nas veias do autor de Memórias póstumas de Brás Cubas um fator determinante para a qualidade de sua obra como escritor. Sem entrar no mérito questionável dessa argumentação de cunho biológico, o que interessa destacar é que o entendimento do negro na citação acima revela um aspecto do contato de Oswald de Andrade com o ambiente cultural francês. Ele demonstra estar plenamente consciente do processo de valorização de culturas não europeias em curso naquele momento, algo que se confirma no trecho final da conferência, quando comenta as realizações dos músicos brasileiros em Paris: "jamais se sentiu tão bem em Paris o som dos tambores do negro e do canto do indígena. Essas forças étnicas estão em plena modernidade" ${ }^{30}$. 
Diante dessas colocações, é possível sugerir que, no momento em que preparou a conferência, Oswald de Andrade se encontrava em meio a um processo de revisão do modo como percebia a posição ocupada por negros e indígenas na formação cultural do Brasil. Seu entendimento sobre essa questão apresenta ainda resíduos de ideias inferiorizantes - a passividade e a infantilidade. Ao mesmo tempo, ele procurava se apropriar de um fenômeno histórico com o qual acabava de entrar em contato: o "primitivismo" das vanguardas europeias e a "negrofilia" existente em Paris ${ }^{31}$.

Aqui, pode ser útil abrir uma breve digressão. Um elemento da negrofilia europeia das primeiras décadas do século XX que, recentemente, tem sido discutido em chave crítica, é o processo de espetacularização dos corpos de mulheres e homens africanos, que, desde o século XIX, assumiu diversas formas no contexto dos espetáculos de massa não apenas na França, mas em outros países europeus e nos Estados Unidos. Nos ethnic e freak shows, nos "zoológicos humanos" das exposições universais e coloniais ${ }^{32}$, nas arenas de boxe, nos cabarés e no teatro, assim como em toda a iconografia que esses eventos mobilizavam, produzia-se uma verdadeira indústria de exibição da alteridade étnica, em que o corpo negro oscilava entre o exótico, o selvagem, o lúbrico e o monstruoso.

Pode ser lembrado aqui, a título de exemplo, a trajetória do ator e dançarino Habib Benglia, nascido na Argélia, que ganhou notoriedade na década de 1920 pelas performances de dança que protagonizava no cabaré Folies Bergères e por sua atuação em peças como Le loup de Gubbio (1921), Cyclone (1923), L'empereur Jones (1923). Ou os boxeadores estadunidenses Jack Johnson, Dixie Kid ou Sam Mac Vea, que podiam ser vistos em arenas armadas em circos. Como aponta Sylvie Chalaye, em artigo que focaliza a recepção desses eventos, neles a verdadeira atração era o corpo negro:

O público branco se vê confrontado com o corpo do Outro: o corpo negro do boxeador americano sobre a arena do circo, como aquele do guerreiro zoulou que veio aos Folies Bergères ou aquele da dançarina ashanti ao Jardin zoológico de aclimatação, ou ainda aquele do escaramuçador senegalês que desfila pela primeira vez na capital em Longchamp, em 1899. E não é o soldado, não é o boxeador, não é o dançarino ou o guerreiro que os parisienses observam, mas verdadeiramente a corporeidade "negra" de
Thiago Gil de Oliveira Virava

Vantagens do caos brasileiro:

- Brasil que Oswald de

Andrade descobriu em Paris.

31. Sobre esta última palavra, Petrine Archer-Straw afirma:

“' 'Negrofilia', do francês négrophilie, significa um apreço pela cultura negra. Nos anos 1920, o termo foi usado positivamente pela vanguarda parisiense para afirmar seu apreço provocador pelo negro.

A origem da palavra, no entanto, não é tão lisonjeira. Ser chamado de 'negrófilo' ou 'amante dos negros' no século 19 era ser condenado como um apoiador de atitudes liberais a respeito da escravidão e da abolição. Ainda mais negativamente, negrófilos eram por vezes acusados de ter um apetite sexual depravado por negros, situando-os, assim, fora dos limites morais da sociedade 'civilizada' [...] Tal como usada pelas vanguardas parisienses, a palavra pretendia ser provocativa e desafiadora dos valores burgueses". In: ARCHER-STRAW, Petrine.

Negrophilia: Avant-Garde Paris and Black Culture in the 1920s. New York: Thames \& Hudson, 2000, p. 9-10, tradução nossa.

32. Cf. BLANCHARD, P.; BANCEL, N.; BOËTSCH, G.; DEROO, É.; LEMAIRE,

S. Zoos humains et exhibitions coloniales. 150 ans d'inventions de l'Autre. Paris: La Découverte, 2011. Ver, em especial, os capítulos “La Vénus hottentote ou la naissance d'un 'phénomène' " e “'Exhibition' et médiatisation de l'Autre: le jardin zoologique d'acclimatation (1877-1890)". 
33. CHALAYE, Sylvie. Théâtre et cabarets: le "nègre" spectacle. In: BLANCHARD, P.; BANCEL, N.; BOËTSCH, G.; DEROO, É.; LEMAIRE, S.

Zoos humains et exhibitions coloniales. 150 ans d'inventions de l'Autre. Paris: La Découverte, 2011. p. 400.

34. Ibidem. uma presença que impressiona (...) São corpos para se ver, corpos autênticos, em carne e osso, objetos de apresentação que se oferece à curiosidade do público. O corpo negro feito espetáculo. ${ }^{33}$

Esse fenômeno pode ser entendido, ainda segundo Chalaye, como projeção de uma "fantasia erótica" que agitava os 1920 e contrapunha corpos brancos e negros:

Empacotados em seus ternos cor de grafite, sufocados nos corsets que lhes comprimem o peito, burgueses e burguesas olham o corpo do "negro" ou da "negra" como um corpo livre e disponível (...) Uma nudez para se ver com toda liberdade porque ela ocupa a cena em nome do espetáculo, e sobretudo de um certo realismo etnográfico. ${ }^{34}$

Nessa fantasia, não faltou espaço para um entendimento do corpo negro não apenas como lúbrico, mas também como bestial. É o que Chalaye identifica nas críticas publicadas na imprensa francesa, entre outubro e novembro de 1923, a respeito da atuação de Habib Benglia como protagonista da peça L'empereur Jones, escrita pelo estadunidense Eugene O'Neill e montada naquele ano pelo ator e diretor francês Firmin Gémier, no Odéon-Théâtre. Segundo a autora, o público se sentia atraído mais pela performance atlética de Benglia do que por suas qualidades como ator:

Não se retém a performance do ator, mas a agitação que provoca a corporeidade de sua presença. Em Le Carnet, René Wisner reconhece o talento de Benglia, mas em termos que o reduzem curiosamente a uma condição animal: "Ele tem espasmos e sobressaltos de besta capturada. Todo seu corpo se dobra, se recompõe, salta e cai novamente. Ele faz de sua academia negra um poema exprimindo a aflição ou a esperança. Um ator atua com seu cérebro e seu rosto, já o Sr. Benglia atua com seus músculos [...] É impossível ser mais sincero, estar mais próxima da animalidade, e ser mais artista”.35

Para Chalaye, o uso desse tipo de vocabulário animalizante sugere que entre as exposições etnológicas do Jardin Zoológique d'Acclimatation e o palco dos teatros e cabarés havia pouca ou nenhuma diferença para o olhar do espectador. 
Retomando o fio da argumentação proposta aqui sobre a conferência de Oswald de Andrade, o que se quis destacar com as considerações acima é que a "descoberta" das esculturas, máscaras, lendas e cantos africanos por artistas e escritores das vanguardas históricas se deu em meio e participou desse processo mais amplo de construção social de uma alteridade étnica baseada na projeção de uma identidade "selvagem" sobre corpos de indivíduos africanos ou afrodescendentes e sobre suas produções culturais.

Ao mencionar apenas os cantos ou o rufo dos tambores, sem se ocupar de seus significados, não há qualquer indício no pensamento do escritor de um interesse por essas práticas como algo mais do que a simples expressão de "forças étnicas". A modernidade do negro e do indígena, na visão por ele projetada a partir do que vivenciava em Paris, residia em manifestações exteriores do que ele entendia serem duas "forças étnicas" brasileiras. Por essa razão, pode-se argumentar que, ao valorizar aquelas práticas culturais apenas dessa maneira, ainda que com intenção de alçá-las à condição de realidades que colocavam o Brasil "em plena modernidade", Oswald de Andrade as apresentava como imagens exóticas, reconhecíveis e agradáveis ao gosto primitivista do público de sua conferência ${ }^{36}$.

Além do realismo dos romances de Machado de Assis, a influência do "sangue negro" é lembrada na conferência também em relação a outros elementos da cultura brasileira. $\mathrm{O}$ sentimento nacional anunciado pelos poetas coloniais era na verdade algo que se produzia por toda a parte,

nos cantos negros, nos cantos caboclos, para se diluir, na ingenuidade primitiva de ritmos pobres, em Casimiro de Abreu. Este é o primeiro cantor da nossa melancolia de raças exiladas no meio de um paraíso mal conquistado. ${ }^{37}$

Na sequência, são apresentados alguns autores ligados ao regionalismo, como Ricardo Gonçalves, Cornélio Pires e Catulo da Paixão Cearense, que buscavam se aproximar "da verdade nacional, anunciada pelos cantos anônimos dos sertões, a cantiga nostálgica do vaqueiro, do almocreve, do negro e do caipira". A "verdade nacional" estava anunciada, portanto, aos que quisessem ouvi-la, pelos "cantos anônimos dos sertões” e por seus personagens. De modo que o esforço intelectual do Brasil contemporâneo é resumido por Oswald de Andrade da seguinte maneira: "Dada nossa matéria psicológica e nosso
Thiago Gil de Oliveira Virava

Vantagens do caos brasileiro:

o Brasil que Oswald de

Andrade descobriu em Paris.

36. Cabe lembrar aqui que, também em 1923, Tarsila do Amaral pinta A Negra, obra que, como as considerações de Oswald de Andrade na conferência da Sorbonne, também pode ser entendida como uma tentativa de resposta ao ambiente negrófilo parisiense. Uma análise nesse sentido é apresentada no capítulo “De Babilônia ao Pau Brasil", da tese Um boxeur na arena: Oswald de Andrade e as artes visuais no Brasil, de que foi extraído este artigo.

37. ANDRADE, Oswald de. 0 esforço intelectual do Brasil contemporâneo (1923). Op. cit., 2011, p. 45. 

ano 16 a estas riquezas adquiridas uma expressão e uma forma que podem n. 33 dirigir nossa arte para o apogeu.”38 Nesse trecho, já é possível antever ideias que reaparecerão condensadas no Manifesto da Poesia Pau-Brasil. $\mathrm{O}$ esforço do Brasil contemporâneo era libertar-se da submissão às "influências importadas" e aproveitar as riquezas de expressão que já 38. Ibidem, p. 46. possuíamos para construir uma arte verdadeiramente nacional.

Concluindo sua apresentação na Sorbonne, Oswald de Andrade faz alguns comentários sobre a escultura, a pintura e a música brasileiras. Para Aracy Amaral, no que diz respeito às artes visuais, a conferência apresentava apenas dois méritos: "o reconhecimento da atualidade do exótico na França e a rejeição positiva da atividade da Missão Fran-

39. AMARAL, Aracy. Op. cit., p. 108-109.
40. ANDRADE, Oswald de. L'effort intellectuel du Brésil contemporain. Op. cit., jul. 1923, p. 206. Na versão publicada na Revista do Brasil, todo o trecho até "de fato" foi suprimido. cesa em nosso país no século XIX"39. Se o primeiro ponto, pelo que foi visto até aqui, está correto, pode ser útil verificar a pertinência do segundo ponto. De fato, como aponta Amaral, Oswald de Andrade afirma que o direcionamento da pintura brasileira no sentido de uma arte "sem personalidade” era um efeito da atuação dos artistas ligados à missão. Mas, no mesmo parágrafo em que isso é dito, há também outras opiniões não menos importantes sobre a história da pintura no Brasil:

Se Debret teve o bom senso de reunir a seus assuntos anedóticos - ele era um discípulo de David -, os elementos da nacionalidade nascente e o sentido decorativo indígena, o pintor português Da Silva e os outros mestres da missão francesa dirigiram nossa pintura para um sentido de velho classicismo deslocado que fez, até nossos dias, uma arte sem personalidade. De fato, como na literatura, a lembrança das fórmulas clássicas impediu longamente a livre eclosão de uma verdadeira arte nacional. ${ }^{40}$

Como se vê, Oswald de Andrade menciona o sucessor de Joachim Lebreton na direção da Escola Real de Ciências, Artes e Ofícios, o pintor Henrique José da Silva, ao lado dos "outros mestres da missão francesa", como aqueles que levaram a pintura brasileira a uma arte sem personalidade, deslocando Debret de uma participação direta nesse processo. Poucas linhas antes do parágrafo citado acima, ele já havia feito a seguinte colocação: "Na pintura, criada no Rio por Debret, que fazia parte da missão francesa de cultura contratada por dom João VI, há toda uma tradição do retrato e de assuntos históricos”. Para o escritor, portanto, a pintura no Rio de Janeiro havia 
sido criada por Debret. Seria, no mínimo, injusto ignorar um posicionamento como esse, apenas para manter intacta a imagem de um modernista que negava qualquer valor ao passado acadêmico.

Se, de fato, como demonstram suas posições a respeito da Academia e suas "chapudas lições", Oswald de Andrade tinha muitas restrições à produção dos artistas por ela formados ${ }^{41}$, seu posicionamento sobre Debret contribui para tornar mais complexo seu entendimento da história da pintura no Brasil. Embora o escritor não comente qualquer trabalho do pintor, a obra de Debret é entendida como uma primeira tentativa de inclusão tanto de "elementos da nacionalidade nascente", quanto de um "sentido decorativo indígena", o que permite pensar que a pintura do artista francês era, para o escritor, a primeira tentativa consciente de produzir uma arte singular, com "personalidade" ${ }^{42}$.

Ainda sobre Debret, é possível inferir, embora a frase não torne isso explícito, que sua pintura teve um papel significativo para o surgimento da "tradição do retrato e de assuntos históricos" mencionada por Oswald de Andrade. Talvez, pelo contexto em que se dava a conferência, a menção a um pintor francês - discípulo de David, como o autor fez questão de frisar - como criador de uma tradição pictórica no Brasil tenha sido uma maneira de forjar mais um vínculo que unia o país à tradição clássica francesa. No entanto, será justamente "a lembrança das fórmulas clássicas” um fator apontado por Oswald de Andrade como bloqueio à produção de uma verdadeira arte nacional.

Após comentar a má influência de Henrique José da Silva e dos demais "mestres da missão francesa", Oswald de Andrade complementa:

Sempre a obsessão da Arcádia com seus pastores, sempre os mitos gregos ou então a imitação das paisagens da Europa, com seus caminhos fáceis e seus campos bem alinhados, tudo isso numa terra onde a natureza é rebelde, a luz é vertical e a vida está em plena construção. ${ }^{43}$

Pode parecer que quem fala no trecho acima é o Oswald de Andrade autor do artigo "Em prol de uma pintura nacional", que criticava, em 1915, a atitude frente à natureza tropical dos pintores paulistas que estudavam na Europa custeados pelo Pensionato Artístico, apontando Almeida Júnior como precursor e modelo a ser seguido. Mas não é mais. Agora, os precursores foram deslocados para um período anterior à atuação do pintor ituano; são os artistas coloniais e

\section{Thiago Gil de Oliveira Virava}

Vantagens do caos brasileiro:

o Brasil que Oswald de

Andrade descobriu em Paris.

41. A menção, na conferência, aos processos de Pedro Américo e do casal Lucílio e Georgina de Albuquerque, como algo superado pela nova geração de artistas brasileiros é mais um exemplo disso.

42. Anteriores a Debret, são mencionados os "precursores" Leandro Joaquim e Olímpio da Mata. Oswald de Andrade se refere a um trabalho perdido do primeiro como "a obra-prima da nossa pintura antiga".

43. ANDRADE, Oswald de. Op. cit., p. 51-52. 
ARS Debret. Já os modelos para a pintura brasileira contemporânea eram

ano 16

ก. 33

44. Ibidem, p. 52.

45. ANDRADE, Oswald de. L'effort intellectuel du Brésil contemporain. Op. cit., jul. 1923, p. 206, Trecho suprimido na versão publicada na Revista do Brasil.

46. Já foi indicado acima o quanto a apresentação de "O esforço intelectual do Brasil contemporâneo" pode ser entendida como um momento estratégico no estabelecimento, por Oswald de Andrade, de contatos junto ao meio intelectual francês. Há em todo o texto um objetivo

bastante nítido de mostrar a qualidade e o valor do esforço intelectual e artístico brasileiro. Esse objetivo, possivelmente, o levou a incluir na apresentação algumas posições que, em outro contexto, ele talvez não assumisse. Esse parece ser o caso das pinturas de Rego Monteiro. Em carta enviada a Mário de Andrade, agora procurados em Paris: "Os novos artistas, precedidos por Navarro da Costa, começaram a reação adotando os processos modernos, oriundos do movimento cubista da Europa"44.

Considerado "um protesto contra a arte imitadora dos museus", o cubismo, como Oswald de Andrade se preocupa em esclarecer, não vinha sendo adotado de forma inconsciente e acrítica pelos jovens artistas brasileiros. É o que sugere a seguinte afirmação: "E se é absurdo de aplicá-lo [o cubismo] no Brasil, as leis que ele soube extrair dos antigos mestres foram consideradas aceitáveis para muitos de nossos jovens pintores" ${ }^{\text {"45 }}$. Com base nessa colocação, é possível inferir que, do encaminhamento "clássico" da pintura cubista no início da década de 1920, Oswald de Andrade julgava mais relevante reter as "leis", dando pouca atenção aos temas das obras, por exemplo, de Picasso nesse período. Isso, de certo modo, aponta para os limites da aproximação com o "espírito latino" proposta na conferência. Daquele espírito seria preciso reter o equilíbrio construtivo, as "leis" descobertas pelos cubistas nos mestres clássicos. Quanto aos assuntos, estes deveriam ser buscados em outras referências.

É o que sugerem os breves comentários de Oswald de Andrade no parágrafo em que menciona os artistas brasileiros que pesquisavam os processos modernos. De Anita Malfatti, ele destaca "os procedimentos enérgicos"; de Di Cavalcanti, "a fantasia"; de Rego Monteiro, a pesquisa da "estilização de nossos motivos indígenas, procurando criar ao lado de uma arte pessoal, a arte decorativa do Brasil”46; e, por fim, de Tarsila do Amaral, a estética que "alia os temas do interior brasileiro aos procedimentos mais avançados da pintura atual”47. Não era, portanto, nas figuras da mitologia clássica que os artistas brasileiros buscavam inspiração, mas nos "motivos indígenas" e no "interior brasileiro".

Além dos pintores e pintoras, Oswald de Andrade também destacou na conferência o escultor Victor Brecheret. Mas não sem antes mencionar, como fizera com a pintura, os precursores coloniais, entre os quais ele cita o "entalhador de pedras do estado de Minas", Aleijadinho, e os "primeiros criadores de imagens" da Bahia e do Rio de Janeiro, Chagas, o Cabra, e Mestre Valentim. Para Oswald de Andrade, era dessas fontes que Victor Brecheret tentava extrair sua arte ${ }^{48}$. Ao comentar a peça Ídolo, o escritor destaca o quanto nessa escultura Brecheret dirigia "suas linhas e seu estilo para a estatuária negro-indiana da colônia" ${ }^{4}$. Dessa forma, Brecheret é apresentado por Oswald de Andrade como um 
artista pesquisador de uma tradição nacional na escultura. Uma tradição alheia aos escultores formados pela Academia; uma tradição marcada, como na literatura e nos cantos populares, pelo "sangue negro".

Para concluir esses apontamentos sobre a "descoberta" do Brasil feita por Oswald de Andrade em Paris, pode ser útil analisar dois artigos enviados da capital francesa ao jornal carioca Correio da Manhã. São eles "Vantagens do caos brasileiro" e "Preocupações brasileiras", publicados, respectivamente, em 12 e 20 de dezembro de 1923.

No primeiro texto, é apresentado um diagnóstico da experiência criativa de escritores brasileiros, baseado no artigo "Poesia velha, poesia nova, poesia eterna”, de Amadeu Amaral, que discutia o problema do "transplante" de "modelos alienígenas" constantemente realizado pelos movimentos literários brasileiros. A posição de Amaral era de que mesmo imitando exterioridades dos modelos europeus que importavam, os escritores brasileiros nunca deixavam de ser brasileiros. Ainda que "vestidos à francesa”, todos permaneciam

brasileiros dos quatro costados (...) com toda a conformação, todos os defeitos, todas as qualidades, todas as manias, todas as virtudes, todas as heranças e tendências conscientes e inconscientes que um meio e uma nacionalidade imprimem nas mais profundas entranhas das almas nativas, sujeitos, por submissão ou sem ela, às contingências da vida que se processa, independente quand même, dentro das fronteiras de um país geográfico, política e moralmente definido. ${ }^{50}$

Esse entendimento de Amadeu Amaral sobre a experiência intelectual brasileira abria a Oswald de Andrade a oportunidade de diagnosticar o que ele nomeia de caos brasileiro. Um caos que abrangia desde o campo institucional, com um parlamento britânico transplantado para o império de D. Pedro II no século XIX, até a arquitetura, "que representa trezentos e trinta tipos de cidades humanas". Tudo isso era fruto do que o escritor batiza de "psicologia de exposição universal", que tudo acolhia com uma "tolice infantil", "cheia de audácia, de pesquisas, de seiva casamenteira" ${ }^{51}$.

No entanto, ainda que reconhecesse o valor daquela "seiva casamenteira" que imperava na atitude psicológica brasileira, Oswald de Andrade apontava um perigo que ameaçava o verdadeiro caminho intelectual do país. Era o perigo da submissão a "certo gosto exterior apreendido", que consistia em abandonar "nossa escolha natural e

\section{Thiago Gil de Oliveira Virava}

Vantagens do caos brasileiro:

- Brasil que Oswald de

Andrade descobriu em Paris.

em 4 de março de 1923, na qual comentava o Salon des Indépendants, Oswald de Andrade se refere às obras da exposição nos seguintes termos: "o salão dos independants [sic], a última arrancada, já ridícula, já triste, da modernidade ocidental. Não é mais cubismo, é cú... ismo. Lhote, Léger, Gleizes, Lipchits [sic] comandando esquadrões de Regos Monteiros. Uma palhaçada!". Se no Salon des Indépendants ele havia identificado "um esquadrão de Regos Monteiros", portanto uma arte indiferenciada e sem personalidade, produzida em série sob a batuta dos mestres cubistas, é difícil imaginar que alguns meses depois ele percebesse na obra do artista pernambucano a arte pessoal apontada na conferência.

47. ANDRADE, Oswald de. L'effort intellectuel du Brésil contemporain. Op. cit., jul. 1923, p. 206. Trecho suprimido na versão publicada na Revista do Brasil.

48. A conexão das esculturas de Brecheret às de artistas coloniais como Chagas, o Cabra e Aleijadinho já havia sido sugerida por Mário de Andrade anos antes, em texto sobre o escultor, publicado na revista llustração Brasileira:

“São Paulo, mais uma vez e em outro terreno, vai glorificar-se, reatando uma tradição artística que 
ARS flutuante, para nos submeter a uma perigosa deformação aparente-

ano 16

n. 33

o Aleijadinho de Vila Rica, o gênio inculto do

portal de São Francisco de

Assis, em Ouro Preto, e da

escadaria de Congonhas

encetou e que nenhum ousara continuar. E Brecheret, cujas forças artísticas rapidamente se maturam ao calor de impecilhos e rivalidade, não só renova o passado em que

a Bahia deu Chagas, o Rio

Mestre Valentim e Minas João

Francisco Lisboa, como realiza o ideal moderno da escultura, templo onde pontificam Boudelle, Lembruck, Carl Milles e Mestrovic". ANDRADE, Mário de. De São Paulo. Illustração Brasileira,

Rio de Janeiro, ano 8, n. 3, nov.

1920 , s.p.

49. ANDRADE, Oswald de. 0 esforço intelectual do Brasil contemporâneo (1923). Op. cit., 2011, p. 51.

50. Idem. Vantagens do caos brasileiro. Correio da Manhã, Rio de Janeiro, 12 dez. 1923.

Disponível em: <http:// hemerotecadigital.bn.gov.br/>.

Acesso em: 1 mar. 2018. 0 trecho é do artigo de Amadeu Amaral, citado por Oswald de

Andrade.

51. lbidem.

52. Ibidem.

53. Ibidem.

54. Ibidem. mente ortopédica”. Na escolha dos modelos exteriores a incorporar, era preciso saber obedecer ao que o "organismo" nacional conseguisse extrair de "elementos brasileirantes" daqueles modelos:

Possuímos, afinal, um organismo, pois é ele que procura, elege, aceita, absorve e transforma. Esse organismo já tem mesmo algumas características marcadas pela adaptação no ambiente da vitalidade orgânica de certos modelos que ou vieram nas raças de formação ou com elas melhor coincidiram. ${ }^{52}$

Essas características marcadas ou "tendências já definidas e mesmo chegadas a um caráter de tradição" seriam: "em música, o ritmo do índio e o canto negro; nas artes plásticas, a ingenuidade dos mulatos místicos; na literatura, o 'folclore" ${ }^{53}$. Por "mulatos místicos" entende-se que Oswald de Andrade se refere aos artistas coloniais - Aleijadinho, Chagas, o Cabra e Mestre Valentim, mencionados em sua conferência na Sorbonne. Era a partir dessa "base" nacional, dessa "tradição" já estabelecida que se deveria orientar a escolha de modelos.

Na sequência de "Vantagens do caos brasileiro", o escritor aponta alguns elementos que poderiam ser tomados como exemplos daquela submissão "ortopédica” a modelos exteriores. E um deles está relacionado à pintura:

A nossa pintura, começada pela religiosidade ingênua e dura dos primitivos e desgraçadamente interrompida por um século de servilismo acadêmico, não pode e não deve, por motivos de luz e de geografia, seguir o impressionismo e a doçura do mestres franceses e italianos do século passado. ${ }^{54}$

Assim, o mesmo perigo de correção "ortopédica” daquelas que seriam as tendências "naturais" da pintura no Brasil, estabelecidas pela tradição colonial, estava presente tanto nos modelos acadêmicos quanto nos impressionistas. Estar ciente disso, no entanto, não implicava renegar o que acontecia na Europa. Ao contrário, para o escritor era urgente entender o fenômeno de "descoberta" da América que vinha se processando naquele continente:

A Europa descobriu definitivamente a América e deixou-se facilmente sugestionar pela forte novidade da vida veloz e prática do novo continente. 
Apenas, sendo um mais aperfeiçoado cadinho, já produziu nas suas elites o que a América ainda apresenta em bruto como arte e literatura. ${ }^{55}$

Assim, o cubismo francês será por ele entendido como produto da "máquina americana", assim como as músicas de Erik Satie e Igor Stravinski, "saíram das liberdades do 'jazz' americano”. Eram as elites europeias lapidando o que América oferecia em estado bruto.

Nesse contexto de aproveitamento intelectual das novas experiências estéticas promovidas pela modernidade, em conjunto com o que a América oferecia de "forte novidade", o gosto de Monteiro Lobato pela pintura de um Paul Chabas aparecia a Oswald de Andrade como uma monstruosidade estética. Do autor de Ideias de Jeca Tatu, no entanto, era preciso aproveitar, como símbolo, o personagem Jeca Tatu, mas purificando-o das "intoxicações" de Lobato. Era preciso mostrar ao "doente" Jeca Tatu que ele "não vale menos como pintor que Corot, o grande representativo da passada doçura francesa" ${ }^{56}$.

Toca-se aqui em um ponto importante desse artigo pouco conhecido de Oswald de Andrade. A argumentação de que a pintura de um Jeca Tatu valia tanto quanto a de um Jean-Baptiste Camille Corot era uma defesa da pintura popular, muito anterior à valorização no Brasil dos pintores ditos "ingênuos". O escritor apresenta essa ideia contando uma de suas experiências vividas em Paris, no apartamento de Darius Millhaud:

Esperando Darius Milhaud, o conhecido músico da vanguarda parisiense, em uma visita que lhe fiz, vi na parede, ao lado de uma natureza morta de Picasso e de um desenho de Delacroix, duas paisagens curiosíssimas com montanhas, palmeiras e casas. Milhaud fez-me ler a assinatura 'Jacaré', embaixo dos desenhos e acrescentou:

- O Brasil não sabe o que tem. Essas deliciosas pinturas que coloco, sem medo, em meu apartamento de Paris, ao lado de Picasso e Delacroix, foram compradas por quase nada no porto da Bahia. O dia em que vocês descobrirem que é esse o caminho da pintura brasileira, poderão conquistar um lugar interessante no mundo. ${ }^{57}$

Pouco antes de contar essa experiência que abriu seus olhos para um possível e ignorado "caminho da pintura brasileira”, Oswald de Andrade havia lembrado em seu artigo do "interessante primitivo baiano que se chamou Olímpio da Matta e dos seus inúmeros sucessores anô-
Thiago Gil de Oliveira Virava

Vantagens do caos brasileiro:

o Brasil que Oswald de

Andrade descobriu em Paris.

55. Ibidem.

56. Ibidem.

57. Ibidem 

liam tanto quanto um Corot e que a existência da Academia Imperial e, depois, da Escola Nacional de Belas Artes, contribuía para que permanecessem ignorados ${ }^{59}$. O escritor termina o artigo com uma convoca-

58. Ibidem.

59. Se o casal Lucílio e Georgina de Albuquerque é outra vez lembrado como exemplo de artistas acadêmicos que "não representam nem o Brasil, nem a França, nem coisa de definido sentido", e a missão artística francesa é apontada novamente como a responsável pela “longa escravatura artista [sic]" que em vez de "melhorar e instituir a técnica pictórica entre nós, deu de destruir o admirável espírito de nossa pintura nascente", Oswald de Andrade preocupa-se em ressalvar "a exceção curiosa de Debret”. A menção a Debret como exceção à "malfadada e pretensiosa missão de d. João VI" reafirma, portanto, a opinião do escritor sobre a importância do pintor francês

para a história da pintura no Brasil, que ele já havia apontado em sua conferência na Sorbonne.

60. ANDRADE, Oswald de. Preocupações brasileiras. Correio da Manhã, Rio de Janeiro, 20 dez. 1923.

Disponível em: <http:// hemerotecadigital.bn.gov.br/>. Acesso em: 1 mar. 2018.

61. Ibidem ção: "Sejamos antes caóticos, mas livres, que um dia seremos pessoais". Em "Preocupações brasileiras", Oswald de Andrade retoma o problema do "caos" próprio ao interesse dos intelectuais brasileiros por modelos estrangeiros. Dessa vez, porém, concentra-se nas duas instituições - Escola Nacional de Belas Artes e Academia Brasileira de Letras - que engendravam, em sua opinião, o que esse caos poderia produzir de mais nefasto: a submissão. O texto aborda mais os problemas literários, discutindo o quanto ações instituídas pela Academia contribuíam para a difusão do "caos" da mentalidade nacional. Em meio a essas considerações, porém, surgem algumas observações sobre pintura, dentro de um interesse sobre um novo modo de olhar produzido pela vida moderna.

Esse novo modo de olhar, surgido "da oficina mecânica, de bateria coletivista, produzida pela vida atual das grandes cidades com metropolitanos, organização esportiva, aviões, problemas de circulação, etc.”, vinha sendo experimentado nas artes e literatura europeias ${ }^{60}$. Ele consistia em uma atitude que Oswald de Andrade chama de "volta aos objetos". Uma volta aos objetos que não tinha qualquer preocupação seja de enobrecê-los ou de menosprezá-los:

Desapareceu de fato, com a falsa aristocracia do sublime que defendia de cabeleira os passos de ópera e as atitudes de cançoneta, essa mania de nobilitar ou horrificar [sic] a vida comum de nossos dias.

Assim, de Cézanne para cá, pintam-se mesas, garrafas, copos, jornais. E foi essa volta aos objetos que fez achar aos atuais artistas a grande tradição da pintura, perdida pelos cabeludos ignaros e sentimentais do último século. ${ }^{61}$

Era preciso aprender com essa "volta aos objetos" e reassumir frente ao mundo uma atitude semelhante à que teriam experimentado nossos primeiros escritores e artistas "nativos". E para isso, era preciso

esquecer quase tudo quanto aprendemos - das maléficas ternuras de Lord Byron aos paradoxos invertidos de Wilde, das tolices materialistas de 
Flaubert, às estéticas embrulhadíssimas de além Reno.

Voltemos corajosamente aos mulatos místicos e urbanos da Bahia, de Pernambuco, de Minas. ${ }^{62}$

Só assim seria possível fazer valer "nosso organismo pesquisador, absorvente, irrequieto", que fazia com que queimássemos nossas "pestanas tropicais atrás de questões que afetam a psique mórbida do norte da Europa”. Só assim seria possível fazer emergir do caos de modelos e referências que nossa "seiva casamenteira" unia indiscriminadamente, algo de fato original, válido, "pessoal”. Estava traçado o roteiro do programa estético Pau-Brasil. A história que se seguiu já é bem conhecida. Mas, de algum modo, ainda está sendo escrita. Perceber como as artes visuais foram parte constitutiva da elaboração do pensamento de Oswald de Andrade sobre a inserção da cultura brasileira na cultura moderna - e vice-versa - pode acrescentar algumas linhas (ou abrir alguns parênteses) nessa história.

\section{Bibliografia}

AMARAL, Aracy. Tarsila: sua obra e seu tempo. 3a ed. rev. e ampl. São Paulo: Ed. 34; Edusp, 2003.

ANDRADE, Mário de. De São Paulo. Illustração Brasileira, Rio de Janeiro, ano 8, n. 3, nov. 1920.

ANDRADE, Oswald de. L'effort intellectuel du Brésil contemporain. Revue de l'Amérique Latine, Paris, ano 2, n. 5, p. 207, jul. 1923.

. Vantagens do caos brasileiro. Correio da Manhã, Rio de Janeiro, 12 dez. 1923. Disponível em: <http://hemerotecadigital.bn.gov.br/>. Acesso em: 1 mar. 2018.

. Preocupações brasileiras. Correio da Manhã, Rio de Janeiro, 20 dez. 1923. Disponível em: <http://hemerotecadigital.bn.gov.br/>. Acesso em: 1 mar. 2018.

O esforço intelectual do Brasil contemporâneo (1923). In:

Estética e Política. Organização, introdução e notas Maria Eugenia Boaventura. 2a ed. rev. e ampl. São Paulo; Globo, 2011.

. Poesias reunidas. 1a ed. São Paulo: Companhia das Letras, 2017.
Vantagens do caos brasileiro:

o Brasil que Oswald de

Andrade descobriu em Paris.

62. Ibidem 
ARCHER-STRAW, Petrine. Negrophilia: Avant-Garde Paris and Black ano 16

n. 33 Culture in the 1920s. New York: Thames \& Hudson, 2000.

BATISTA, Marta Rossetti. Os artistas brasileiros na Escola de Paris: anos 1920. São Paulo: Editora 34, 2012.

BERCHENKO, Adriana. La Revue de l'Amérique latine en los años 20. América: Cahiers du CRICCAL, n 4-5, p. 21-26, 1990.

BOAVENTURA, Maria Eugenia. 22 por 22: A Semana de Arte Moderna vista pelos seus contemporâneos. São Paulo: Editora da Universidade de São Paulo, 2008.

BLANCHARD, P.; BANCEL, N.; BOËTSCH, G.; DEROO, É.; LEMAIRE, S. Zoos humains et exhibitions coloniales. 150 ans d'inventions de l'Autre. Paris: La Découverte, 2011.

CALIL, Carlos Augusto. Sob o signo do Aleijadinho. Blaise Cendrars, precursor do patrimônio histórico. Arquitextos, São Paulo, ano 13, n. 149.05, Vitruvius, out. 2012. Disponível em: <http:/www.vitruvius.com. br/revistas/read/arquitextos/13.149/4540>. Acesso em: 11 jan. 2018.

CAMARGOS, Marcia. Entre a vanguarda e a tradição: os artistas brasileiros na Europa (1912-1930). São Paulo: Alameda, 2011.

DINIZ, Dilma Castelo Branco. A gênese da Poesia Pau-Brasil: um escritor brasileiro na França. O Eixo e a Roda: Revista de Literatura Brasileira, Belo Horizonte, v. 9-10, p. 75-83, 2003-2004. Disponível em: $<$ http:/www.periodicos.letras.ufmg.br/index.php/o_eixo_ea_roda/article/ view/3159>. Acesso em: 1 mar. 2018.

SILVER, Kenneth E. Esprit de corps. The art of the Parisian AvantGarde and the First World War, 1914-1925. Princeton: Princeton University Press, 1989.

Thiago Gil de Oliveira Virava é Doutor em História, Crítica e Teoria da Arte pela Universidade de São Paulo (2018), com pesquisa sobre a relação de Oswald de Andrade com as artes visuais. Mestre na mesma linha de pesquisa (USP, 2012), com estudo sobre a percepção do movimento surrealista no Brasil. Entre 2011 e 2016, foi colaborador da Enciclopédia de Artes Visuais do Instituto Itaú Cultural como pesquisador e redator. É autor do livro Uma brecha para o Surrealismo (Alameda, 2015). Desde 2013, é pesquisador

da Fundação Bienal de São Paulo.

Artigo recebido em 20 de junho de 2018 e aceito em 08 de julho de 2018. 